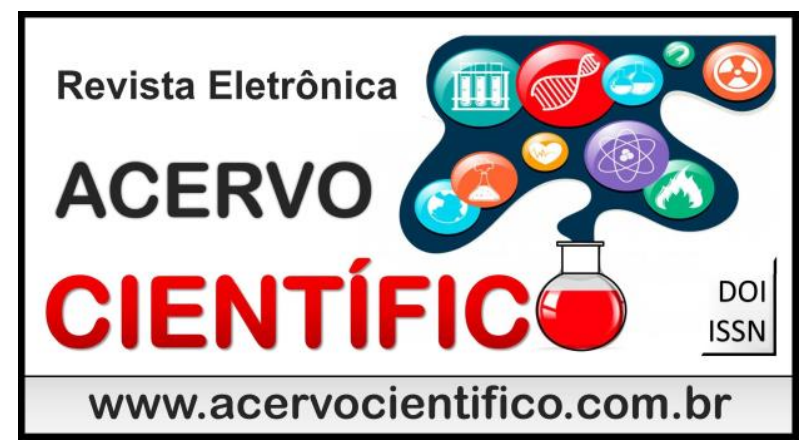

ARTIGO DE REVISÃO

Recebido em: 2/2019

Aceito em: $3 / 2019$

Publicado em: 4/2019

\title{
O PAPEL DO PERITO JUDICIAL E O ASSISTENTE NO DEVIDO PROCESSO LEGAL
}

Role of judicial expert and assistant in due process of law

El papel del experto judicial y el asistent en el debido proceso lega

Aldiane Rodrigues Miranda ${ }^{1}$, Erlenilce Oliveira de Sousa ${ }^{2}$

\begin{abstract}
Resumo: Esse artigo buscou relatar em uma pesquisa qualitativa a importância do Perito Judicial. Foi realizada a pesquisa com referêncial teórico metodológico bibliográfico atravez de Evangelista (2000), Filho \& Filho (2010), Da Costa (2015) e outros importantes autores. Os resultados encontrados é que teoricamente não existe opinião formada sobre a questão da importância, porém é clara e evidente nas fontes pesquisadas que é necessário uma técnica oficial ou ad hoc nas áreas da perícia judiciária para auxiliar o poder da justiça e ser mais exato nos casos concretos em busca da verdade. Conclui-se que esta pesquisa é de cunho importantíssimo para que os peritos e auxiliares mantenham-se cada vez mais a formação em evidência, e busquem se aprimorarem para estar auxiliando o poder judiciário e assim prestando mais eficiência e eficácia, que é incontestado a importância e sua técnica em auxilio na esfera criminal e judiciária do país.
\end{abstract}

Palavras-chave: Auxiliares da justiça. Perícia criminal. Perito judicial.

Abstract: The objective of this paper is to report on a qualitative research the importance of the forensic expert. The research was conducted with a bibliographic methodological theoretical reference through the Evangelist (2000), Son \& Son (2010), Da Costa (2015) and other important authors. The results found is that theoretically there is no opinion formed on the issue of importance, but it is clear and evident in the sources researched that it is necessary an official or ad hoc technique in the areas of judicial expertise to assist the power of justice and be More accurate in concrete cases in search of truth. It is concluded that this research is very important for the experts and auxiliaries to keep the training in evidence increasingly, and seek to improve themselves to be assisting the judiciary and thus providing more efficiency and efficacy, which is Undisputed importance and its technique in assisting the criminal and judicial sphere of the country. judicial sphere of the country.

Keywords: Justice assistants. Criminal expertise. Judicial expert.

\footnotetext{
${ }^{1}$ Faculdade de Educação de Bacabal (FEBAC), Bacabal-MA. * E-mail: enaid2008@hotmail.com.

2 Instituto de Pós-Graduação \& Graduação (IPOG), Imperatriz-MA.
} 
Resumen: El objetivo de este trabajo es informar sobre una investigación cualitativa de la importancia del experto forense. La investigación se llevó a cabo con una referencia teórica metodológica bibliográfica a través del evangelista (2000), son \& son (2010), da Costa (2015) y otros autores importantes. Los resultados obtenidos son que teóricamente no hay una opinión formada sobre la cuestión de la importancia, pero es claro y evidente en las fuentes investigadas que es necesario una técnica oficial o ad hoc en las áreas de la experiencia judicial para ayudar al poder de la justicia y ser Más precisos en casos concretos en busca de la verdad. Se concluye que esta investigación es muy importante para los expertos y auxiliares para mantener la formación en evidencia cada vez más, y tratar de mejorar a sí mismos para ayudar al poder judicial y por lo tanto proporcionar más eficiencia y eficacia, que es Indiscutible importancia y su técnica en la asistencia al ámbito penal y judicial del país.

Palabras clave: Auxiliares de justicia. Forense criminal. Experto forense.

\section{INTRODUÇÃO}

O objetivo deste trabalho é relatar em uma pesquisa qualitativa contemporânea e a importância do Perito Judicial, mais precisamente, como é sua importância em tal procedimento em estudos da Ciência Forense não apenas nas áreas das multiciências ou criminal, como tradicionalmente é utilizado.

O questionamento que se faz, ou a problematização desta pesquisa, pergunta-se qual a relevância e importância do perito e do auxiliar de perícia judicial? As hipóteses é que será necessário um especialista em diversas áreas para auxiliar o poder judiciário para dar um resultado mais eficiente em busca da verdade? Ou quem sabe o perito e o auxiliar podem direcionar habilidosamente a razão da verdade na situação de casos e ocorrências criminais que o judiciário não pode solucionar? Ou talvez seja mera formalidade técnica?

O processo de revisão da literatura sobre o estudo sobre o trabalho de perícia e seu assistente frente às decisões e encargos judiciais requer a elaboração de um estudo pautado em diferentes conteúdos, capaz de desenvolver uma ampla compreensão sobre o conhecimento. A revisão bibliográfica sobre a literatura que aborda o assunto é um cuidado sobre a pesquisa para a construção do conhecimento científico, onde, através dele se cria $o$ processo do surgimento dos resultados e teorias a serem pesquisadas e questionadas.

Para atingir o objetivo proposto, neste artigo será apresentada, por primeiro, a revisão bibliográfica sistemática; depois, serão apresentados os conceitos sobre a Prática e o Gerenciamento Baseado em Evidências. Posteriormente, discutem-se as metodologias para a revisão da literatura nos estudos organizacionais e, por fim, apresenta-se o método da revisão integrativa como uma proposta a ser incorporada na prática da revisão da literatura nos estudos organizacionais.

Realizada a pesquisa com referencial teórico metodológico bibliográfico através de Evangelista (2000), Filho \& Filho (2010), Da Costa (2015) e outros importantes autores que serão discutidos no decorrer do trabalho.

O potencial deste trabalho é inovador devido à sua interdisciplinaridade, já que visa contextualizar metodologias utilizadas no campo da saúde e que podem ser incorporadas aos estudos organizacionais, principalmente no tocante à busca pelo estado da arte desse tema específico.

Os resultados encontrados sobre este questionamento é que teoricamente não existe uma opinião formada sobre a questão da importância, porém, é clara e evidente nas fontes pesquisadas que é 
necessário uma técnica oficial ou "ad hoc" nas áreas da perícia judiciária para auxiliar o poder da justiça a ser mais exato nos casos concretos em busca da verdade.

Sendo assim veremos nos capítulos a seguir os levantamentos realizados na bibliografia e a discussão dos resultados coletados e transcritos neste trabalho.

\section{MÉTODOS}

Para a elaboração deste estudo, utilizou-se de pesquisa descritiva, com abordagem qualitativa dos dados, através de um estudo bibliográfico.

Quanto aos procedimentos, esse estudo classifica-se como pesquisa bibliográfica, realizando a investigação por meio de livros, artigos em fontes confiáveis, como google acadêmico, e fontes de instituições que tenham vasto conteúdo e elevada estima no assunto abordado, descrevendo informações referentes ao processo de perícias através dos peritos "ad hoc" ou peritos oficiais, bem como o levantamento de perícias quando envolvidas a serviço da justiça.

Será uma pesquisa sistematizada no assunto a relatar, Greenhalgh (1997, p. 672) como uma síntese de estudos primários que contém objetivos, materiais e métodos claramente explicitados e que foi conduzida de acordo com uma metodologia clara e reprodutível.

Os dados necessários para a pesquisa foram obtidos de três formas: (1) Pesquisa junto aos sítios eletrônicos dos Tribunais de Justiça; (2) sites especializados no assunto e (3) livros e bibliografia básica sobre perícias judiciais.

De acordo com Botelho et. al. (2011), a utilização das diferentes formas de coleta de dados justifica-se pela impossibilidade de obter as informações de forma padronizada para toda a pesquisa proposta. Existem diferentes formas de se realizar uma revisão da literatura. Elas baseiam-se desde em técnicas como a revisão bibliográfica tradicional, também conhecida como revisão narrativa, alicerçada no uso de métodos específicos que visam à busca de um assunto específico em acervos da literatura, até no uso de mecanismos e metodologias utilizados por acadêmicos e pesquisadores nos campos da saúde e educação para descrever o estado da arte de um tema.

Neste sentido é necessário diversificar para buscar com mais acuidade os resultados mais próximos da realidade. Sendo assim busca-se com o método descritivo e bibliográfico, solucionar o questionamento desta pesquisa e elucidar o ponto de vista sobre as perícias judiciais e o papel dos auxiliares, ou seja, os assistentes.

\section{RESULTADOS}

Conforme Montenegro (2007) a perícia é um dos meios de prova que visa esclarecer ou evidenciar fatos ao Magistrado a respeito de conhecimentos técnicos, que extrapolam o conhecimento científico do julgador, podendo ser de qualquer natureza e originada de todo e qualquer ramo do saber.

A perícia materializa-se por meio de laudo, constituído de peça escrita, que tem por base o material examinado (MIRANDA et al. apud FILHO \& FILHO, 2010).

Para COSTA (2015), a perícia criminal, diligência prevista pela legislação brasileira quando da ocorrência de fatos supostamente delituosos que deixam vestígios, tem a finalidade de estabelecer por meio de provas a veracidade ou a falsidade de situações ou acontecimentos de interesse da Justiça. 
De acordo com Kempner (2013) a importância da perícia judicial tanto dos peritos quanto de auxiliares no serviço judicial é válido para aumentar as probabilidades de não errar em decisões judiciais, principalmente aquelas que a população necessita de uma resposta rápida e apurada dos fatos.

Os peritos arguidos e "ah hoc" ou oficias por instituições ou órgãos públicos, não arcam com as despesas e custas periciais, emanados pelo poder judiciário, ou em situações de interesse de particular é honorário de responsabilidade do poder privado, ou seja, do particular.

Segundo EVANGELISTA (2001), dependendo da natureza da ação e dos quesitos a serem respondidos, o juiz nomeará um perito, podendo as partes, por sua vez, indicar assistentes técnicos, os quais estes últimos terão como finalidade acompanhar sistematicamente os exames executados pelo perito judicial, participar das audiências quando determinado pelo juízo para aclarar os fatos de investigações técnicas.

PETILLE e SILVA (2016), consideram o perito um importante auxiliar na resolução de conflitos judiciais. Sua tarefa é trazer à luz da Justiça as questões acerca de conhecimentos de sua área profissional quando a resolução da divergência extrapolar os conhecimentos técnicos do Juiz.

Para EVANGELISTA (2000), quando se emprega a interdisciplinaridade científica nas perícias judiciais, consideramos que não basta o bom senso e adequada orientação técnica. É necessário ao perito munir-se de conhecimentos teóricos sobre áreas afins, tais como: Direito, Psicopatologia Forense, Medicina Legal, Antropologia, Serviço Social, Criminologia, Psicologia Clínica, Social, Psicométrica etc., a fim de apreender toda a riqueza que a situação pericial oferece e exige do especialista.

Conforme SOUSA (2013), tem-se por conhecimentos diversas áreas que podem o perito atuar, então legítima todas as áreas do conhecimento a serem habilitadas para os serviços de perícia. Assim seus procedimentos devem ser habilidades técnicas nas áreas de formação e conhecimento legal da sua aplicação no devido processo legal pelas partes e também pelo juiz de causa. A perícia é um procedimento especial de contestação, prova ou demonstração científica ou técnica, relacionada com a veracidade de uma situação ou análise. Quem realiza o ato pericial é o perito que, no âmbito cível, é nomeado pelo juiz para realização de tal procedimento, é aquele que se especializou em determinado ramo ou assunto, que tem experiência ou habilidade em determinada atividade

De acordo com Juliano (2018) para o perito ter sucesso ele deve ter um conhecimento técnico apurado e desenvolvido ao longo do tempo, e para estas características devem observar dois aspectos; o primeiro faz relação à parte técnica que faz parte da perícia judicial, devendo estar bem entendido da parte burocrática forense com o conhecimento das partes assistentes, aos procedimentos nos exames ou nas vistorias, à apresentação de laudo e aos modos de peticionar, já o segundo aspecto diz respeito a questão técnica do conhecimento técnico pessoal, específico da área profissional do indivíduo, adquirido a partir da faculdade e desenvolvido com seu aperfeiçoamento e estudos prolongados sobre os assuntos inerentes a formação profissional.

Segundo Evangelista (2000), quanto à sistematização do laudo pericial (quando o perito é nomeado e compromissado nos autos) ou ainda, parecer ou informe psicológico pericial (não exigindo termo de compromisso, sendo em geral uma resposta a uma indagação da justiça ou a de um pedido de exame complementar ou ainda na condição de assistente técnico) nas diferentes ações ou procedimentos legais, recomenda-se, em geral, os seguintes passos: Autoridade Requisitante; Processo no; Registro do Órgão; Natureza da Ação; Nome do periciado; Nome do perito e seu CRP; Objeto de estudo; Metodologia; Qualificação; Histórico; Antecedentes pessoais, familiares e profissionais; Exames 
complementares; Informe Psicológico; Discussão/conclusão; Respostas aos quesitos (quando houver); atar e assinar.

Conforme descrito no Art. 156 do Novo Código de Processo civil (CPC), sobre o rito de perícia judicial, na seção II diz sobre o perito que; O juiz será assistido por perito quando a prova do fato depender de conhecimento técnico ou científico.

Nesta situação sua nomeação vem também legitimada e taxada no seu parágrafo seguinte;

"Art. 156 do Novo Código de Processo civil (CPC); § 10 Os peritos serão nomeados entre os profissionais legalmente habilitados e os órgãos técnicos ou científicos devidamente inscritos em cadastro mantido pelo tribunal ao qual o juiz está vinculado."

Sobre as obrigações de deveres do perito, no Artigo 157 do Novo Código Processo Civil descreve o dever de cumprir seu ofício sob a pena de no prazo determinado não realizar mais perícias técnicas no judiciário ou prestar mais este serviço, seguidos pelos parágrafos primeiro e segundo do mesmo artigo;

"Art. 157. O perito tem o dever de cumprir o ofício no prazo que Ihe designar o juiz, empregando toda sua diligência, podendo escusar-se do encargo alegando motivo legítimo. $\S 10$ A escusa será apresentada no prazo de 15 (quinze) dias, contado da intimação, da suspeição ou do impedimento supervenientes, sob pena de renúncia ao direito a alegá-la. $\S 20$ Será organizada lista de peritos na vara ou na secretaria, com disponibilização dos documentos exigidos para habilitação à consulta de interessados, para que a nomeação seja distribuída de modo equitativo, observadas a capacidade técnica e a área de conhecimento."

No que diz respeito ao assistente pericial é que se trata de encargo do auxiliar do perito, porém com atividades inerentes diferentes, e o assistente não pode modelar todo trabalho pericial, ficando a cargo do perito oficial, ou "ah hoc", neste caso o assistente sua função além de auxiliar é desenvolver o parecer da perícia técnica, enquanto o perito realizar a descrição do laudo técnico de perícia.

São Profissionais diferentes, no entanto, se fundamentam cada um na legalidade e nas suas funções, assim o laudo é uma prova pericial e o parecer também será auxiliando na justiça e também nas partes envolvidas.

Conforme Gonçalves (2013) a forma pericial, mesmo o perito sendo um auxiliar "Assistente" da justiça, este não deve arcar com o ônus da realização de uma perícia. Isso serve também aos assistentes da perícia, entendimento jurisprudencial para ação de honorário e custas com o perito e assistente.

Conforme descritos por Petille \& Silva (2016);

"É sabido que os recursos dos Tribunais de Justiça são limitados e que estados com menor aporte financeiro têm dificuldades em alocar recursos para criação de rubrica específica para pagamento de assistentes da justiça, mas não pode o Estado conceder direitos sem haver contrapartida financeira, então se reitera afirmação que o perito e demais auxiliares não podem garantir tal direito a terceiros prejudicando-se a si mesmos" (PETILLE \& SILVA, 2016). 


\section{DISCUSSÃO}

Ao fazer o levantamento bibliográfico, obteve-se conteúdo sobre perícia e o descritor sobre peritos, digam-se de passagem em diversas áreas do conhecimento como: odontologia, administrativo, contábeis, médico, de engenharia e outros, no entanto observou pouco conteúdo tratando sobre o assunto relacionando a perícia judicial e assistente auxiliar, ou mesmo com questões de fundamentação legais, estas últimas fundamentadas pelo Novo Código de Processo Civil (2002).

Nota-se que os autores trabalhados neste artigo relatam embasamento no Novo Código de Processo Civil (NCPC), e também na Constituição Federal do Brasil de 1988.

Foram trabalhados alguns aspectos de levantamento nesta pesquisa, a saber; o contexto legal, 0 embasamento técnico de perito e do auxiliar técnico, ou mesmo assistente legal em casos judiciais, e a importância e relevância destes especialistas no caso concreto.

No contexto legal, observa-se que pela constituição é aferido pelo princípio da ampla defesa e contestação do estrito dever de defesa às partes. Neste sentido a perícia técnica bem como provas periciais também constituem provas legais em defesa ou acusação. Embasados também pelo Novo Código de Processo Civil, afere-se também a continuidade dos serviços periciais, dando tanta importância que não se exige mais a formação em nível superior, basta-se apenas ter notório conhecimento na área que for ser realizada a perícia e ter comprovações técnicas e em alguns casos exigir-se-á ás provas de experiências e trabalhos realizados na área que for realizada a perícia técnica ao judiciário.

Sobre a situação do perito e dos assistentes observa-se que os peritos é parte neutra e deve manusear o andamento das perícias judiciais sob o cunho da verdade e obter ao máximo a veracidade dos fatos para o melhor exaurimento do processo e de decisões do magistrado sob o desenvolvimento do laudo pericial final, no entanto, os assistentes emanados pelo poder de auxiliar o perito e também de dirigir o parecer final este deve apenas conduta de fidelidade à parte do processo para direito em sua ampla defesa e constituindo provas também, sendo esta uma prova técnica, o parecer.

Sobre o crivo da importância deve-se este ser irredutivelmente relevante, pois o mesmo é necessário para melhor apuração de fatos e o magistrado virem a fazer uma decisão com conduta pautada na melhor forma legal e também com a verdade mais próxima.

\section{CONSIDERAÇÕES FINAIS}

Com este estudo, podemos abstrair do conteúdo explicado, que, exige-se a técnica dos peritos e assistentes em casos concertos para melhor resultado em prol da verdade e também como ferramenta indispensável ao magistrado e aos juizados que necessita dos serviços, sejam de peritos oficiais ou peritos delegados.

Recomenda-se para pesquisas futuras, desenvolver nas áreas de pericias judiciárias um aprofundamento sobre qual o melhor resultado comparativo para peritos e assistentes judiciais antes e depois das modificações no código de processo civil, realizando assim um estudo comparativo.

Conclui-se que esta pesquisa é de cunho importantíssimo para os peritos e auxiliares, para que se mantenham cada vez mais a formação em evidência, e busquem se aprimorarem para poder estar auxiliando o poder judiciário e assim prestando mais eficiência e eficácia, é incontestada a importância e sua técnica em auxílio na esfera criminal e judiciária do país. 


\section{REFERÊNCIAS}

1. BRASIL. Câmara dos deputados: Centro de Documentação e Informação. Constituição Federal da República Federativa do Brasil. 1988.

1. 2. . DA COSTA PEG. Medicina legal e criminalística. Brasília: Vestcon; p. 21-5. 2010.

2. 3. EVANGELISTA R. Algumas considerações sobre as perícias judiciais no âmbito civil. Revista IMESC 2000, (2): 51-57.

3. FILHO PEGC. FILHO EA. Diretrizes éticas na prática pericial criminal. Revista Bioética 2010; 18(2): 421-437.

4. GONÇALVES AP. A perícia judicial gratuita e a postergação ou a não remuneração do perito: em busca de uma solução constitucional mais humana. Revista Científica do Departamento de Ciências Jurídicas, Políticas e Gerenciais do UNI-BH. 2010; 3(1).

5. JULIANO R. Manual de Perícias: Segundo o novo Código de Processo Civil. Editora: Roteiro de pericias, 2018: 640.

6. KEMPNER, DB. A importância da prova pericial. Revista Especialize On-line IPOG. 2013; 01(5).

7. MIRANDA KCO, DA COSTA FILHO PEG, GUTIÉRREZ CG. Medicina legal: resumo e questões 2. comentada. Brasília: Vestcon; 2007.

8. MONTENEGRO FM. Curso de direito processual civil: Teoria Geral do processo e processo de conhecimentoSão Paulo: Atlas, 2007; 1(4): 502.

9. PETILLE R. SILVA RHA. Expert routine in dental malpratice litigance: Forensic Odontologist accreditation and fees in Brazil. Perícia odontológica cível. Revista Brasileira de Odontologia Legal - RBOL. 2006. 